\title{
Rabaska
}

Revue d'ethnologie de l'Amérique française

BOUCHARD, JEAN. Jouets au Québec, 1939-1969. Québec, Les

Éditions GID, 2 tomes, 2014-2017 : tome 1 (Du bolo au G.I. Joe :

Jouets au Québec, 1939-1969), 2014, 200 p. ISBN

978-2-89634-234-1 ; tome 2 (Jouets au Québec, 1939-1969. La

seconde parade). Préface de MICHEL LESSARD. 2017, 192 p. ISBN

978-2-89634-354-6

\section{Suzanne Marchand}

Volume 16, 2018

URI : https://id.erudit.org/iderudit/1051344ar

DOI : https://doi.org/10.7202/1051344ar

Aller au sommaire du numéro

Éditeur(s)

Société québécoise d'ethnologie

ISSN

1703-7433 (imprimé)

1916-7350 (numérique)

Découvrir la revue

Citer ce compte rendu

Marchand, S. (2018). Compte rendu de [BOUCHARD, JEAN. Jouets au Québec, 1939-1969. Québec, Les Éditions GID, 2 tomes, 2014-2017 : tome 1 (Du bolo au G.I. Joe : Jouets au Québec, 1939-1969), 2014, 200 p. ISBN 978-2-89634-234-1 ; tome 2 (Jouets au Québec, 1939-1969. La seconde parade). Préface de MICHEL LESSARD. 2017, 192 p. ISBN 978-2-89634-354-6]. Rabaska, 16, 248-250.

https://doi.org/10.7202/1051344ar services d'Érudit (y compris la reproduction) est assujettie à sa politique d'utilisation que vous pouvez consulter en ligne.

https://apropos.erudit.org/fr/usagers/politique-dutilisation/ 
Bouchard, Jean. Jouets au Québec, 1939-1969. Québec, Les Éditions Gid, 2 tomes, 2014-2017 : tome 1 (Du bolo au G.I. Joe : Jouets au Québec, 1939-1969), 2014, 200 p. ISBN 978-2-89634-234-1 ; tome 2 (Jouets au Québec, 1939-1969. La seconde parade). Préface de Michel LeSSARD. 2017, 192 p. ISBN 978-2-89634-354-6.

Certains collectionnent les timbres, d'autres les pièces de monnaie. Jean Bouchard, lui, collectionne les jouets et pas n'importe lesquels. Il s'intéresse aux jouets datant des années 1940, 1950 et 1960 en accordant une importance particulière aux jouets fabriqués au Québec et au Canada. Psychologue de formation et enseignant, Jean Bouchard prend bien soin de mentionner dès le départ qu'il n'est pas un expert, mais plutôt un amateur de jouets anciens. Pourtant, force est de constater qu'il connaît très bien son sujet. Collectionneur averti et passionné, il nous entraîne dans son univers peuplé de bolos, de trottinettes, de poupées, de vire-vents, de traîneaux et de petites voitures, tous plus colorés les uns que les autres.

Dans son avant-propos, l'auteur précise qu'il a privilégié les jouets qui étaient distribués largement au Québec et offerts au plus grand nombre. Il spécifie également que ces jouets ne sont pas présentés en suivant un ordre précis et logique. Il ne faut donc pas s'attendre à retrouver dans ses livres les jouets rares et coûteux conservés précieusement dans les réserves muséales québécoises, ni espérer y découvrir un savant exposé sur l'évolution des jouets au Québec. Ce n'est d'ailleurs pas le but poursuivi par l'auteur qui s'est plutôt donné comme objectif d'éveiller les mémoires et d'amener ses lecteurs à plonger dans leurs souvenirs d'enfance. Et il y parvient très bien grâce notamment aux nombreuses illustrations qui parsèment ses deux volumes. On y retrouve bien sûr plusieurs photographies couleur de jouets issus de sa collection réalisées par Jean Bouchard lui-même et Judith Douville (chargée de projet au Musée de la mémoire vivante); mais il ne s'est pas contenté de ces images, il a poussé la recherche iconographique plus loin en y ajoutant des illustrations provenant de catalogues de grands magasins ou de vieux cartons d'emballage, ainsi que des photographies d'enfants s'amusant avec des jouets datant de la période 1939-1969 trouvées dans différentes régions du Québec. À elles seules, ces images nous transportent dans le temps et nous ramènent à cette époque pas si lointaine où les jouets de fabrication industrielle côtoyaient encore les jouets de facture artisanale.

Au-delà des illustrations, le texte rédigé par Jean Bouchard ne manque pas non plus d'intérêt. Dans le premier volume, intitulé $D u$ bolo au G.I. Joe, il aborde les moments de l'année où l'on offrait des jouets aux enfants, l'importance des catalogues dans la diffusion des jouets, les rites et traditions entourant la distribution des jouets, les classes sociales et leur impact sur les jouets offerts aux enfants, la différence entre les jouets destinés aux filles et 
aux garçons, la provenance des jouets disponibles au Québec au cours de la période étudiée et les matériaux utilisés. Dans le deuxième volume, intitulé La seconde parade, préfacé par Michel Lessard et publié trois ans plus tard, les jeux et jouets sont toujours présents, mais Jean Bouchard s'éloigne un peu de son sujet, en évoquant ses souvenirs personnels et en abordant des thèmes comme l'éducation, les vêtements et la religion.

Ce qui fait le grand intérêt de ces ouvrages, c'est que l'auteur ne se contente pas de présenter les jouets en se limitant à leur description matérielle. Il prend aussi soin d'expliquer comment on les utilisait en rappelant, entre autres, le riche répertoire de comptines qui accompagnaient les jeux de balle ou de corde à danser des petites filles ou les règles à respecter dans certains jeux de billes, des règles et des comptines qu'on retrouvait sensiblement inchangées d'une région à l'autre au Québec et qui font maintenant partie de notre folklore. Il fait aussi ressortir toute l'ingéniosité de nos prédécesseurs pour fabriquer à peu de frais et à partir de matières recyclées des jouets qui faisaient le bonheur des enfants : nécessaire à bulles de savon constitué d'une pipe à tabac usée dans laquelle on soufflait ; tire-roche confectionné avec une partie de branche d'arbre, des retailles de chambre à air de pneu de bicyclette et un bout de cuir pour placer la pierre ; échasses réalisées en utilisant deux boîtes de conserve vides maintenues par de longues cordes ; balançoire constituée d'un pneu usé attaché à une branche d'arbre ; cerfsvolants façonnés avec des bouts de bois, du papier journal et une bande de jute en guise de queue ; carton attaché avec une épingle à linge sur une raie de la roue d'une bicyclette pour imiter le bruit d'une moto; boîtes à savon récupérées pour fabriquer des bolides ; tape-cul composé d'un bout de ski ou d'un morceau de tonneau, d'une bûche et d'une planche faisant office de siège ; petite toupie ou tricotin fabriqué avec une bobine de fil, etc. Et que dire des équipements de sport utilisés à l'époque pour jouer au hockey, comme les jambières fabriquées avec des catalogues retenus par des élastiques sous le pantalon ou encore le crottin de cheval congelé pour remplacer la rondelle !

Il est aussi fascinant d'observer la nette démarcation entre les jouets destinés aux filles et ceux destinés aux garçons qui ressort de ces ouvrages. L'auteur insiste d'ailleurs sur le fait que les jouets des années 1930 à 1960 étaient très stéréotypés, tout comme la société d'ailleurs. Pendant que les petits garçons jouaient aux cow-boys et aux Indiens (chapeaux, arc et flèches à ventouse, pistolets, insignes de shérifs) ou s'amusaient avec des petites autos et des trains électriques, les petites filles, elles, étaient orientées vers le rôle de mère et le travail ménager (maison de poupée, service à thé, machine à coudre, poupée, fer à repasser, batterie de cuisine, berceaux, poussettes, chaises hautes, etc.). Imiter les adultes faisait aussi partie des jeux fréquents à l'époque, les jouets destinés aux petites filles étant là aussi très différents 
de ceux s'adressant aux garçons. Pendant que les petites filles jouaient à la maîtresse d'école (brosse à tableau, tableau, boulier compteur), à la coiffeuse, à la secrétaire, à la téléphoniste ou à l'infirmière, les petits garçons rêvaient de devenir commerçant, menuisier, fermier, garagiste, pompier ou médecin.

Ces ouvrages nous permettent d'autre part de réaliser à quel point les jouets étaient encore à cette époque un luxe auquel tous les enfants n'avaient pas accès. Même s'il existait déjà une grande quantité de jeux et de jouets fabriqués industriellement, il n'était pas rare que les enfants provenant de familles nombreuses et moins fortunées n'aient pas autre chose pour s'amuser que de découper dans les catalogues, empiler des bâtons de popsicle, ou encore classer des boutons par couleur. Certains témoignages recueillis par Jean Bouchard auprès de personnes qui ont grandi à cette époque et qui n'ont pas eu la chance d'avoir beaucoup de jouets sont d'ailleurs très émouvants.

Les jouets présentés dans ces deux volumes ne sont qu'un aperçu de l'immense collection de Jean Bouchard. En publiant ces livres, il ne fait aucun doute que ce grand collectionneur a atteint le but qu'il s'était fixé : nous replonger dans nos souvenirs d'enfance.

Suzanne Marchand Société québécoise d'ethnologie

CAdrin, Gaston. Les Excommuniés de Saint-Michel-de-Bellechasse au XVIII ${ }^{e}$ siècle. Québec, Les Éditions GID, 2015, 405 p. ISBN 978-2-89634-271-6.

Pendant la décennie 1780, cinq personnes ont été inhumées dans un cimetière privé situé sur la terre de Pierre Cadrin au quatrième rang de SaintMichel-de-Bellechasse. Cette terre se trouve aujourd'hui dans les limites de la municipalité de La Durantaye. Les cadavres ont été exhumés un siècle plus tard, ce qui a inspiré à Louis Fréchette son poème « Les Excommuniés ». En 1977, Raoul Roy, un militant indépendantiste reconnu, a publié une brochure sur la question, sous le titre Patriotes indomptables de La Durantaye. Gaston Cadrin explique que ce dernier lui a remis une copie de son travail, ce qui l'a incité, plusieurs années plus tard, à fouiller le sujet lui-même.

La validation de l'identité des " excommuniés » est le point de départ d'une reconstitution des familles des cinq personnes auxquelles le poème de Louis Fréchette fait référence. Le choix du titre du livre ne donne pas la mesure de l'ampleur de la recherche effectuée par Gaston Cadrin, qui décrit, en fait, la vie des colons dans la plaine côtière de Bellechasse au XVIII ${ }^{\mathrm{e}}$ siècle.

Les quatre premiers chapitres retracent la généalogie de la famille Cadrin et des familles qui lui sont alliées par le mariage ou le voisinage. Le « clan de la côte Saint-René » ou du quatrième rang apparaît tissé serré, les alliances 